\title{
Cystic duct patch closure of remnant bile duct in living donor hepatectomy when primary closure is difficult: An easy solution
}

\author{
Subash Gupta, Rajasekhar Kandagaddala, Shaleen Agarwal, Rajesh Dey, \\ Selvakumar Naganathan, Peeyush Varshney, and Nilesh Patil
}

Centre for Liver and Biliary Sciences, Max Super Speciality Hospital, Saket, New Delhi, India

\begin{abstract}
Backgrounds/Aims: In living donor hepatectomy, hepatic duct division is a crucial step and often a technical challenge, with the aim of obtaining a good hepatic duct for anastomosis in the recipient and an adequate stump in the donor for closure. Very rarely, after duct division, the remaining stump may not be adequate for primary closure. In such a difficult situation, the options would be either to close stump transversely or a Roux-en-Y Hepaticojejunostomy. Methods: We describe a novel surgical technique of "Cystic duct patch repair", utilizing the available local tissues for closure of bile duct wall. Results: Two year follow up of this technique showed satisfactory results with no evidence of stricture and normal liver functions. Conclusions: In living donor hepatectomy, "Cystic duct patch closure" may be used if the post closure cholangiogram is not satisfactory. Although the best method is prevention by ensuring a stump for closure, very rarely this error can occur and can be sorted by cystic duct patch repair. (Ann Hepatobiliary Pancreat Surg 2020;24:513-517)
\end{abstract}

Key Words: Cystic duct patch; Living donor hepatectomy; Donor bile duct repair

\section{BACKGROUND}

In living donor hepatectomy, hepatic duct division is a crucial step and often a technical challenge. The balance must be maintained between obtaining a good hepatic duct for anastomosis in the recipient and an adequate stump in the donor for closure. Very rarely, after duct division, the remaining stump may not be adequate for primary closure. In such a difficult situation the options would be either to close the stump transversely ${ }^{1}$ or primary closure over a T-tube ${ }^{2}$ or to do a side to side Rouxen-Y hepaticojejunostomy. ${ }^{3}$ We describe a novel surgical technique of "Cystic duct patch repair", utilizing the available local tissues for closure of bile duct wall. Neck and cystic duct portion of the gallbladder is a well vascularised tissue which is in continuation with the common hepatic duct. This portion of the gallbladder remnant can be safely anastomosed to the transection site on the hepatic duct provided the cholangiogram was done through a part of the gall bladder. This patch repair provides both continuity of flow of bile as well as additional tissue for the bile duct repair.

\section{CASE DESCRIPTION}

We describe a case of 28-year-old donor whose right duct had been cut flush with the common bile duct (CHD). He had Type I Biliary anatomy (as per the classification proposed by Choi et al. ${ }^{4}$ ) on Magnetic resonance cholangiopancreatography (MRCP) and it was confirmed on the intra-operative cholangiogram. The biliary confluence was narrow, and a large caudate duct was joining the right posterior sectoral duct. After parenchymal transection, the marking clip was placed on the proposed right duct transection site and its location with relation to the left hepatic duct and the common bile duct (CBD) was confirmed on the cholangiogram. Subsequently, the Right hepatic duct (RHD) was divided and the right lobe donor

Received: June 22, 2020; Revised: July 10, 2020; Accepted: July 12, 2020

Corresponding author: Subash Gupta

Centre for Liver and Biliary Sciences, $5^{\text {th }}$ floor, West Block, Max Super Speciality Hospital, 1-2 Press Enclave Road, Saket, New Delhi 110017, India

Tel: +91-98110-75683, Fax: +91-11265-10050, E-mail: guptasubash@gmail.com

Copyright (C) 2020 by The Korean Association of Hepato-Biliary-Pancreatic Surgery

This is an Open Access article distributed under the terms of the Creative Commons Attribution Non-Commercial License (http://creativecommons.org/ licenses/by-nc/4.0) which permits unrestricted non-commercial use, distribution, and reproduction in any medium, provided the original work is properly cited. Annals of Hepato-Biliary-Pancreatic Surgery - pISSN: 2508-5778 - elSSN: 2508-5859 
hepatectomy was completed. Bile duct transection site was closed with 6.0 polydioxanone (PDS) continuous sutures. On completion cholangiogram, it was revealed that there was narrowing at the site of closure (Fig. 1). Sutures were dismantled and the transection site was repaired with a

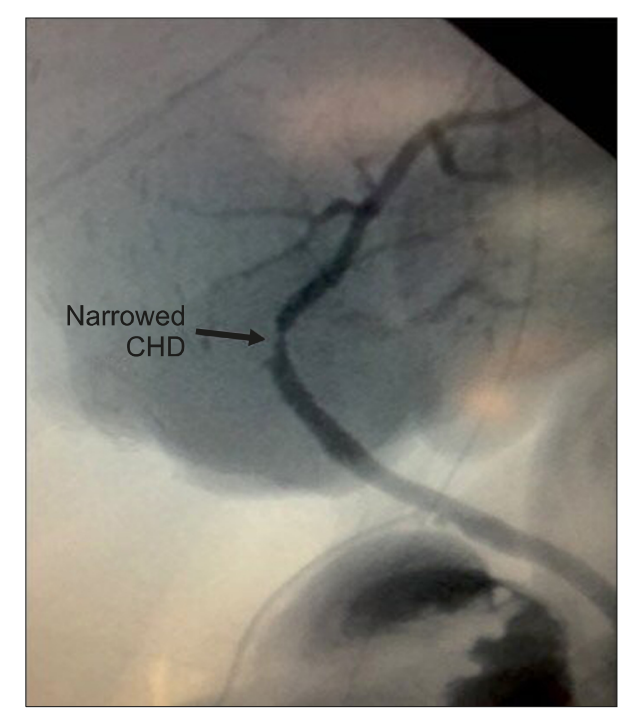

Fig. 1. Transcystic cholangiogram after primary closure showing narrowing in the CHD at right duct transection site. cystic duct patch. Post operatively, he did not develop any bile leak and his liver function tests (LFTs) were essentially normal. During a two year follow up period his liver function tests have been normal. The MRCP after two years did not show any evidence of biliary stricture.

\section{SURGICAL TECHNIQUE OF CYSTIC DUCT PATCH REPAIR}

\section{[FIG. 2 (PICTORIAL) AND Fig. 3 (INTRA-OPERATIVE)]}

The catheter used for cholangiogram was removed and the vascularity of neck and cystic duct of the gall bladder was assessed. The spiral valve of Heister of the cystic duct was dilated with Watson Cheyne probe and free passage into $\mathrm{CBD}$ was established. As the cholangiogram tube had been placed in the Hartmann's pouch of the gall bladder, it was possible to fashion a patch from the gall bladder neck equivalent to the size of defect of the transection site on the CHD. A $12 \mathrm{~F}$ infant feeding tube was passed across the defect into the CHD to get a proper orientation of the corners and then the tube was removed.

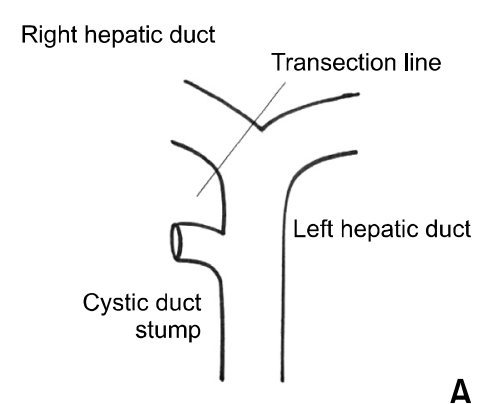

A

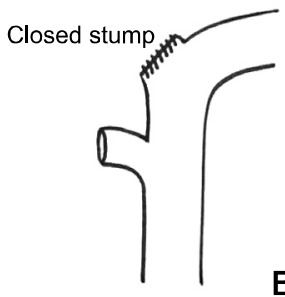

B

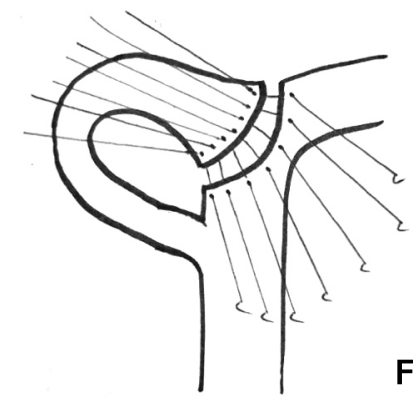

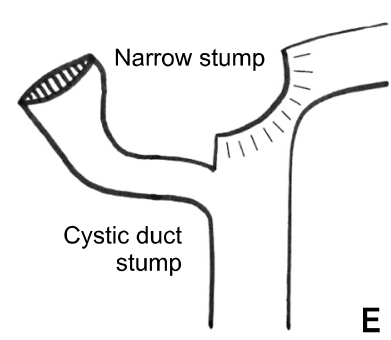

$E$
Right hepatic duct Transection line
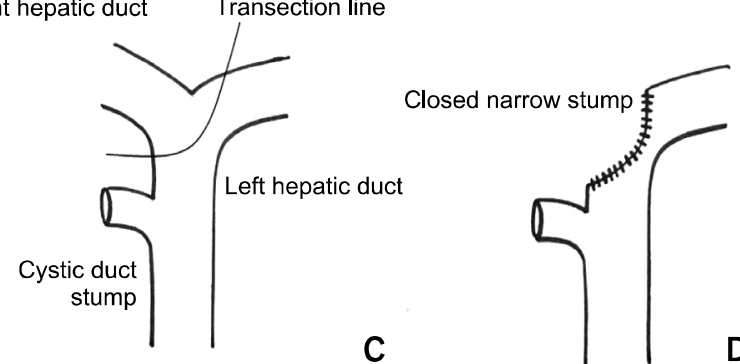

D
$\mathbf{F}$

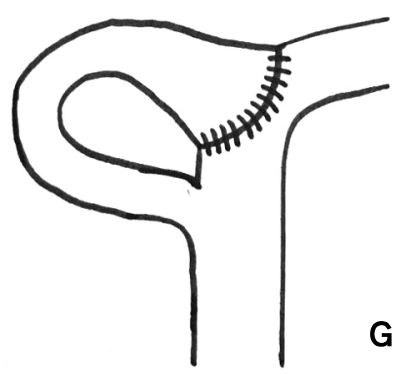

Fig. 2. Pictorial representation of the technique. (A) Normal line of "Right hepatic duct transection." (B) "Right hepatic duct stump closure" and normal left and common hepatic ducts without narrowing. (C) "Right hepatic duct transection" more towards the confluence or left hepatic duct (D) demonstrating "Right hepatic duct stump closure" resulting in "narrowed common hepatic duct." (E) Cystic duct stump after removal of the catheter, (F) cystic duct stump used as a patch closure of the narrowed common hepatic duct at right hepatic duct transection site, $(\mathrm{G})$ common hepatic duct contour after "cystic duct stump and Right hepatic duct stump anastomosis." 

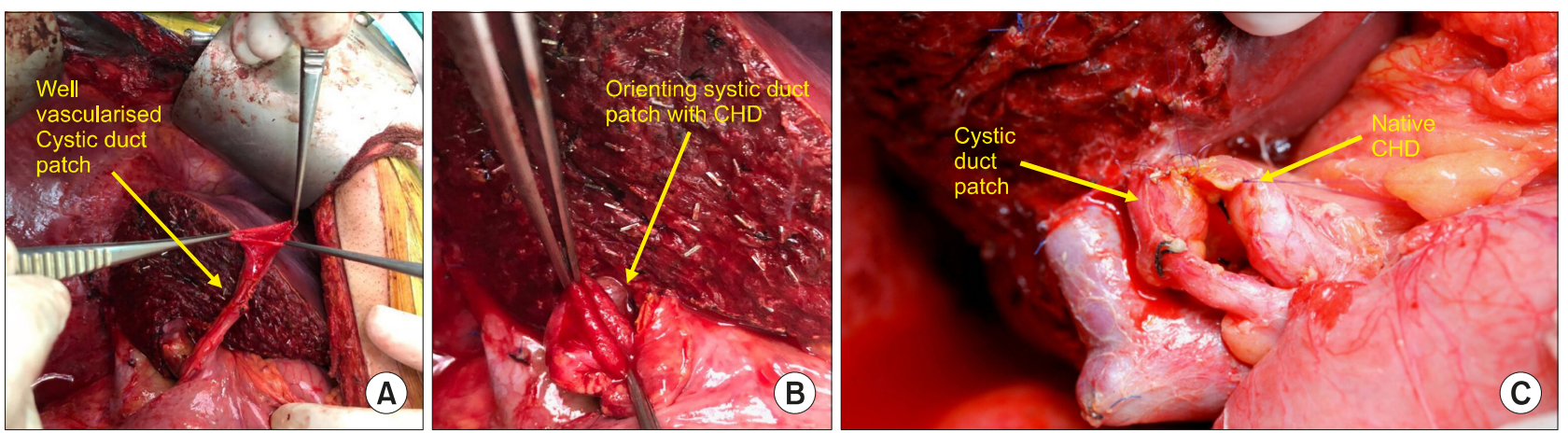

Fig. 3. Intraoperative pictures of "Cystic duct patch-CHD anastomosis."

A single layer tension free anastomosis was done between the wall of gall bladder neck and the defect in the CHD with interrupted 6.0 PDS sutures under loupe magnification. After completion of the anastomosis, 20G peripheral intravenous catheter was placed in the CBD below the anastomosis and a check cholangiogram (Fig. 4) was performed to ensure absence of any anastomotic leak or narrowing of the duct.

\section{DISCUSSION}

Bile duct division is a critical step in living donor hepatectomy. Bile leaks, bilomas and biliary strictures are well known biliary complications in liver donors, and they represent about $20-30 \%$ of total donor complications. In literature, it has been reported that even after standardization of surgical technique, overall biliary complications after living donor hepatectomy ranges between $1.9 \%$ and $14.3 \%{ }^{5-9}$ A recent review estimated that the average incidences of bile leaks and biliary strictures are $4.2 \%$ and $0.8 \%$, respectively. ${ }^{10}$ Biliary complications are often due to misinterpretation of biliary anatomy on cholangiogram. Wang et al. ${ }^{9}$ found that anatomic variations in the biliary anatomy are the most important factors that cause biliary complications. Rarely, these strictures may occur due to duct wall ischemia. In our case, apart from the narrow biliary confluence, a large caudate duct was opening into the right posterior sectoral duct near the confluence. While dividing the right duct, we probably encroached slightly upon the CHD leading to the loss of the stump on the CHD wall. On completion cholangiogram, there was a significant narrowing of the CHD. Various methods of duct division such as "Flouroscopy-guided technique"11

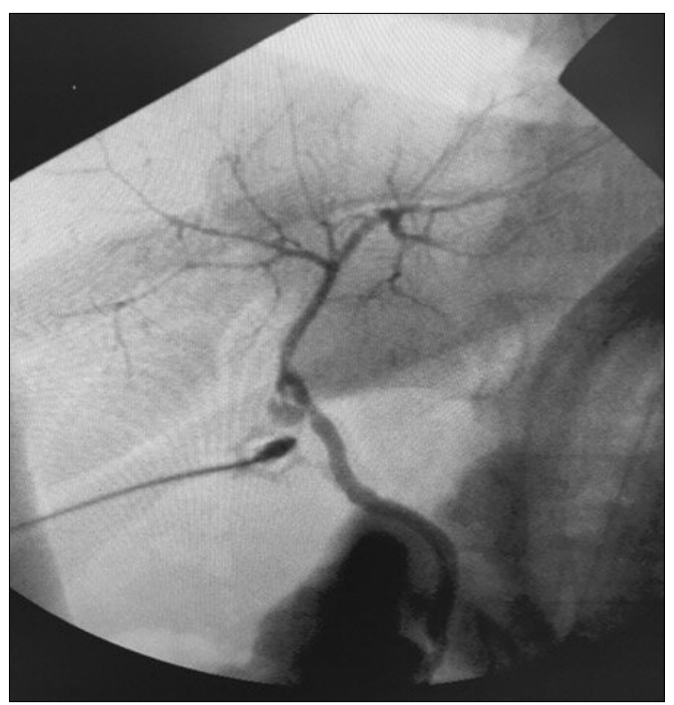

Fig. 4. Check cholangiogram following "Cystic duct patch repair."

and "probe-and-clamp technique"12 have been suggested to avoid this biliary complication. Our technique of bile duct division starts with slight lowering of the hilar plate, after dissecting the hepatic artery and portal vein and marking the ischemic line. We mark the proposed site of duct transection with a large ligaclip and confirm its position on the intraoperative cholangiogram. After completion of the parenchymal transection, we encircle the duct along with the hilar plate with a right-angled dissecting forceps. A second cholangiogram is obtained to confirm the site of transection of the right duct and the duct is divided. After harvesting the graft liver, a completion cholangiogram is performed to check the integrity of the bile duct closure.

In case of suspected narrowing of the donor bile duct on completion cholangiogram, transverse closure similar 

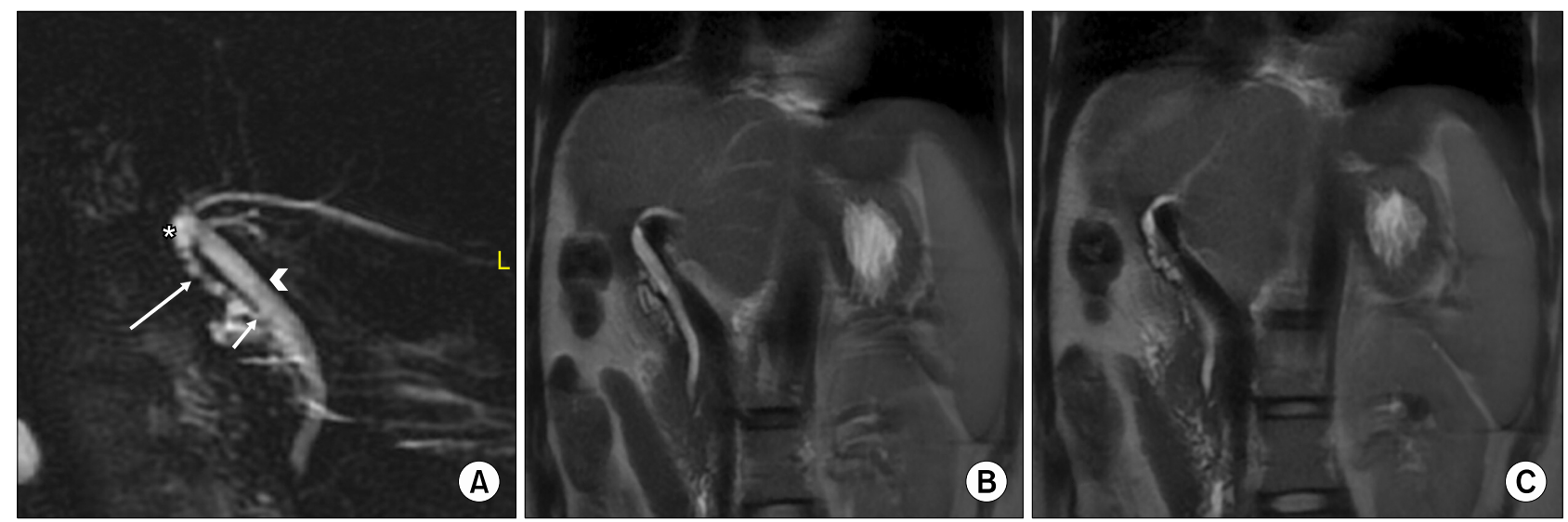

Fig. 5. Follow up MRCP at 2 years, showing no evidence of any stricture in the donor bile duct. (A) Asterisk: cystic duct patch, long arrow: cystic duct, short arrow: cystic duct-CHD junction, arrow head: CHD. (B) MRI: coronal section demonstrating CBD with no stricture or dilatation. (C) MRI: coronal section at different level demonstrating cystic duct patch.

to a pyloroplasty technique ${ }^{1}$ or primary closure over T-tube ${ }^{2}$ or a side to side Roux-en-Y Hepaticojejunostomy ${ }^{3}$ have been suggested to avoid postoperative biliary stricture. However, the transverse closure of duct may result in tension and subsequent bile leak. We propose that the cystic duct patch technique utilizing the available local tissues is a good and effective surgical option. The neck of the gall bladder with the cystic duct acts as an onlay patch to cover the defect on the bile duct wall. It also provides an additional conduit for bile flow across the cystic duct into the CBD. As compared to side to side hepaticojejunostomy, this is a much simpler technique. A two year follow up has shown that this repair has been effective (Fig. 5).

\section{CONCLUSION}

In living donor hepatectomy, "Cystic duct patch closure" may be used if the post closure cholangiogram is not satisfactory. Although the best method is prevention by ensuring a stump for closure, very rarely this error can occur and can be sorted by cystic duct patch repair.

\section{ORCID}

Subash Gupta: https://orcid.org/0000-0002-7782-2593

Rajasekhar Kandagaddala: https://orcid.org/0000-0002-5954-5545

Shaleen Agarwal: https://orcid.org/0000-0002-5187-7799

Rajesh Dey: https://orcid.org/0000-0002-0801-6205

Selvakumar Naganathan: https://orcid.org/0000-0003-3605-4353

Peeyush Varshney: https://orcid.org/0000-0001-6276-1890

Nilesh Patil: https://orcid.org/0000-0003-3029-652X

\section{AUTHOR CONTRIBUTIONS}

Conceptualization and chief surgeon: SG. Assistant surgeons: RK, SN. Writing - Literature review \& original draft: RK. Writing - final editing: SG. Surgical team members: PV, SA, RD, NP.

\section{REFERENCES}

1. Taketomi A, Morita K, Toshima T, Takeishi K, Kayashima H, Ninomiya $\mathrm{M}$, et al. Living donor hepatectomies with procedures to prevent biliary complications. J Am Coll Surg 2010;211:456464.

2. Hwang S, Lee SG, Lee YJ, Sung KB, Park KM, Kim KH, et al. Lessons learned from 1,000 living donor liver transplantations in a single center: how to make living donations safe. Liver Transpl 2006;12:920-927.

3. Stewart L, Way LW. Bile duct injuries during laparoscopic cholecystectomy. Factors that influence the results of treatment. Arch Surg 1995;130:1123-1128; discussion 1129.

4. Choi JW, Kim TK, Kim KW, Kim AY, Kim PN, Ha HK, et al. Anatomic variation in intrahepatic bile ducts: an analysis of intraoperative cholangiograms in 300 consecutive donors for living donor liver transplantation. Korean J Radiol 2003;4:85-90.

5. Shaji Mathew J, Manikandan K, Santosh Kumar KY, Binoj ST, Balakrishnan D, Gopalakrishnan U, et al. Biliary complications among live donors following live donor liver transplantation. Surgeon 2018;16:214-219.

6. Pamecha V, Bharathy KG, Kumar S, Sasturkar SV, Sinha PK. Biliary complications after living donor hepatectomy: a first report from India. Liver Transpl 2016;22:607-614.

7. Ghobrial RM, Freise CE, Trotter JF, Tong L, Ojo AO, Fair JH, et al. Donor morbidity after living donation for liver transplan- 
tation. Gastroenterology 2008;135:468-476

8. Lo CM. Complications and long-term outcome of living liver donors: a survey of 1,508 cases in five Asian centers. Transplantation 2003;75(3 Suppl):S12-S15.

9. Wang SF, Huang ZY, Chen XP. Biliary complications after living donor liver transplantation. Liver Transpl 2011;17:1127-1136.

10. Yuan Y, Gotoh M. Biliary complications in living liver donors. Surg Today 2010;40:411-417.
11. Takatsuki M, Eguchi S, Tokai H, Hidaka M, Soyama A, Tajima $\mathrm{Y}$, et al. A secured technique for bile duct division during living donor right hepatectomy. Liver Transpl 2006;12:1435-1436.

12. Testa G, Malagò M, Porubsky M, Marinov M, Sankary H, Oberholzer J, et al. Hilar early division of the hepatic duct in living donor right hepatectomy: the probe-and-clamp technique. Liver Transpl 2006;12:1337-1341. 